\title{
Synaptic Abnormalities in the Infralimbic Cortex of a Model of Congenital Depression
}

\author{
Ronald R. Seese, ${ }^{1}$ Lulu Y. Chen, ${ }^{1}$ Conor D. Cox,${ }^{1}$ Daniela Schulz, ${ }^{4}$ Alex H. Babayan, ${ }^{1}$ William E. Bunney, ${ }^{2}$ Fritz A. Henn, ${ }^{4,5}$ \\ Christine M. Gall, ${ }^{1,3}$ and Gary Lynch ${ }^{1,2}$ \\ Departments of ${ }^{1}$ Anatomy and Neurobiology, ${ }^{2}$ Psychiatry and Human Behavior, and ${ }^{3}$ Neurobiology and Behavior, University of California, Irvine, \\ California 92697, ${ }^{4}$ Brookhaven National Laboratory, Upton, New York 11973, and ${ }^{5}$ Cold Spring Harbor Laboratory, Cold Spring Harbor, New York 11724
}

\begin{abstract}
Multiple lines of evidence suggest that disturbances in excitatory transmission contribute to depression. Whether these defects involve the number, size, or composition of glutamatergic contacts is unclear. This study used recently introduced procedures for fluorescence deconvolution tomography in a well-studied rat model of congenital depression to characterize excitatory synapses in layer I of infralimbic cortex, a region involved in mood disorders, and of primary somatosensory cortex. Three groups were studied: (1) rats bred for learned helplessness (cLH); (2) rats resistant to learned helplessness (cNLH); and (3) control Sprague Dawley rats. In fields within infralimbic cortex, cLH rats had the same numerical density of synapses, immunolabeled for either the postsynaptic density (PSD) marker PSD95 or the presynaptic protein synaptophysin, as controls. However, PSD95 immunolabeling intensities were substantially lower in cLH rats, as were numerical densities of synapse-sized clusters of the AMPA receptor subunit GluA1. Similar but less pronounced differences (comparable numerical densities but reduced immunolabeling intensity for PSD95) were found in the somatosensory cortex. In contrast, non-helpless rats had 25\% more PSDs than either cLH or control rats without any increase in synaptophysin-labeled terminal frequency. Compared with controls, both $\mathrm{cLH}$ and cNLH rats had fewer GABAergic contacts. These results indicate that congenital tendencies that increase or decrease depression-like behavior differentially affect excitatory synapses.
\end{abstract}

\section{Introduction}

Major depressive disorder (MDD) affects $16 \%$ of the population, with notable costs to patients and society (Kessler et al., 2003). Although the biogenic amine theory has had considerable success (Delgado, 2000; Hirschfeld, 2000), depression is now recognized to be associated with many disturbances (Castrén et al., 2007; Luscher et al., 2011; Samuels and Hen, 2011; Sanacora et al., 2012). Abnormalities in glutamatergic transmission have received considerable attention. Glutamate levels are altered in brains of patients (Sanacora et al., 2004; Yüksel and Ongür, 2010) and rodent models (Hascup et al., 2011; Schulz et al., 2013). Several drugs that affect excitatory synapses have positive effects (Sanacora et al., 2012). Ketamine, which inhibits NMDA-type glutamate receptors, has rapid antidepressant actions (MachadoVieira et al., 2009; Bunney and Bunney, 2012). Positive allosteric modulators of AMPA-type glutamate receptors also decrease depressive-like behavior in animal models (Bai et al., 2001; Li et

Received June 9, 2013; revised July 7, 2013; accepted July 13, 2013.

Author contributions: R.R.S., L.Y.C., C.M.G., and G.L. designed research; R.R.S., L.Y.C., C.D.C., and D.S. performed research;D.S., W.E.B., and F.A.H. contributed unpublished reagents/analytic tools; R.R.S., L.Y.C., C.D.C., D.S., A.H.B., C.M.G., and G.L. analyzed data; R.R.S., C.D.C., C.M.G., and G.L. wrote the paper.

This work was supported by National Institutes of Health Grants NS045260 (C.M.G., G.L.), MH083346 (C.M.G.), T32-GM0862 and FMH095432A (R.R.S.), and MH083396 (L.Y.C.), Laboratory Directed Research and Development Grant LDRD-07-096 (F.A.H.), Office of Naval Research Grant N00014-10-1-007 (G.L.), and National Science Foundation Grant DGE-0808392 (C.D.C.). We thank Yue Qin Yao and Dr. Csaba Varga for their assistance.

F.A.H. is a consultant for Astra Zeneca, and G.L. is a consultant for Afraxis.

Correspondence should be addressed to Dr. Gary Lynch, Department of Psychiatry and Human Behavior, University of California, Irvine, Irvine, CA 92697-1275. E-mail: glynch@uci.edu.

DOI:10.1523/JNEUROSCI.2434-13.2013

Copyright $\odot 2013$ the authors $\quad 0270-6474 / 13 / 3313441-08 \$ 15.00 / 0$ al., 2001) and enhance the potency of monoamine-based antidepressants (Li et al., 2003).

In additional support of the "glutamate hypothesis," dendritic spine density is decreased in hippocampus in acute models of depression (Norrholm and Ouimet, 2001; Hajszan et al., 2009). Similar effects are seen in cortex of chronically stressed rats (Duman and Aghajanian, 2012), but it is not known whether spine counts are decreased in cortical regions associated with depression. A recent postmortem study found that levels markers (synaptophysin, debrin) for glutamatergic contacts are reduced in frontal cortex samples from patients with bipolar disorder (Kim et al., 2010). Similarly, proteins associated with excitatory synapses (PSD95, NR2A, and NR2B) are decreased in homogenates from prefrontal cortex of MDD subjects (Feyissa et al., 2009). Although neither study analyzed synapses, their results suggest that excitatory connections may be reduced in size or decreased in numbers in cortex in association with chronic depression.

The present studies used a recently introduced technology, fluorescence deconvolution tomography, to investigate the above possibilities in a well-characterized model of congenital depression. These methods, which measure large numbers of synapses within 3D reconstructions of sample fields, have been used to test for effects of experimental manipulations on synapse numbers, volumes, and immunolabeling intensities in hippocampus (Rex et al., 2009; Seese et al., 2012). The present study is a first use of this approach to determine whether these synapse measures differ in rodents exhibiting behavioral phenotypes related to affective disorders. Specifically, we evaluated synapses in layer I of infralimbic cortex in rat lines bred over 50 generations to express 
learned helplessness (cLH) or non-helplessness (cNLH) (Schulz et al., 2010). This area is homologous to Brodmann area 25 in humans (Ongür et al., 2003), a region implicated in affective disorders, including depression (Drevets et al., 1997, 2002; Mayberg et al., 1999, 2005; Hajek et al., 2008). Along with behavior that suggests anhedonia (Vollmayr et al., 2004) and a delayed response to antidepressants (Patel et al., 2004), the cLH rats have abnormal glutamate levels (Schulz et al., 2013), altered glutamate metabolism (Shumake et al., 2000), reduced expression of specific excitatory amino acid transporters (Zink et al., 2010), and decreased levels of proteins implicated in excitatory synaptic release (Zink et al., 2007). Thus, the cLH phenotype is particularly appropriate for testing the prediction that chronic depression is associated with significant changes to cortical glutamatergic synapses.

\section{Materials and Methods}

Animals and learned helplessness. Adult rats were bred over 50 generations for expression of congenital learned helpless or non-helpless behavior (Schulz et al., 2010); we used 12- to 18-week-old male rats from our breeding colony (Schulz et al., 2010). Age-matched male Sprague Dawley control rats, supplied by Taconic Farms and housed with the cLH and cNLH lines for at least 2 weeks, were also used. All procedures were approved by the Institutional Animal Care and Use Committees and were conducted in accordance with the National Institutes of Health Guide for the Care and Use of Laboratory Animals.

All cLH and cNLH rats underwent learned helplessness training and testing (Schulz et al., 2010). Skinner boxes with grid floors were used to deliver 120 uncontrollable 5- to 15 -s-long footshocks at $0.4 \mathrm{~mA}$ over a period of $40 \mathrm{~min}$. The next day, rats were tested for helplessness. Each box was equipped with a lever and a signal light; the latter turned on and off with the footshock. Fifteen footshocks were delivered, each lasting $60 \mathrm{~s}$ unless turned off earlier by lever press. Lever presses were automatically recorded by Graphic State (Coulbourn Instruments). The number of lever presses that turned off the footshock within 20 and $60 \mathrm{~s}$ of shock onset and the time to complete the 15 trials were recorded. Animals were considered cLH when they turned off the footshock on no more than five trials and cNLH when they pressed the lever at least eight times within $20 \mathrm{~s}$ of shock onset. At least $24 \mathrm{~h}$ after this testing, rats were deeply anesthetized with isoflurane gas and decapitated. Brains were rapidly removed, frozen in $-45^{\circ} \mathrm{C}$ isopentane, and stored at $-80^{\circ} \mathrm{C}$ until use.

Tissue preparation and immunohistochemistry. Using anatomical landmarks, brains of cLH, cNLH, and age-matched (12-18 week) Sprague Dawley control rats (Schulz et al., 2010) were sectioned using a calibrated cryostat (coronal, $20 \mu \mathrm{m},-20^{\circ} \mathrm{C}$ ) into a library containing multiple series of equally spaced sections spanning the rostrocaudal extent of primary somatosensory forelimb (parietal) neocortex and infralimbic cortex; tissue was fixed in $-20^{\circ} \mathrm{C}$ methanol for $15 \mathrm{~min}$. The rostrocaudal extent of infralimbic cortex is $\sim 1.5 \mathrm{~mm}$, and we sampled $\sim 1.2 \mathrm{~mm}$ of this length using at least four coronal sections separated by $0.3 \mathrm{~mm}$. The positioning of the first section of the series as well as the dorsoventral orientation of sections varied (e.g., from trimming and positioning of the tissue block). Accordingly, results described here should not be considered as coming from precisely matched sections but rather from a series of evenly spaced sample planes located in a quasi-random manner along $\sim 80 \%$ of the infralimbic anteroposterior dimension. Although it was not our intention to create this unstructured variability in locations, modern stereological theory has described advantages of quasi-random sampling for estimating sizes and frequencies of cortical elements (for review, see Dorph-Petersen and Lewis, 2011).

A tissue series was selected at random and then processed for immunofluorescence. The diluent used for primary and secondary antisera consisted of $0.1 \mathrm{~m}$ phosphate buffer containing $4 \%$ BSA and $0.3 \%$ Triton $\mathrm{X}-100$ (Seese et al., 2012). Sections were incubated in primary antisera for $24 \mathrm{~h}$ at room temperature using goat anti-GluAl (1:100; catalog \#sc7609; Santa Cruz Biotechnology) or mouse antisera to PSD95 (1:1000; catalog \#1-1054; Thermo Fisher Scientific), synaptophysin (1:1000; cat- alog \#S5768; Sigma-Aldrich), or the $\mathrm{GABA}_{\mathrm{A}}$ receptor $\left(\mathrm{GABA}_{\mathrm{A}} \mathrm{R}\right) \beta$ subunit (1:200; catalog \#MAB341; Millipore). Alexa Fluor 488 goat antimouse or donkey anti-goat IgG (1:1000; Invitrogen) were used as secondary antisera. Sections were coverslipped with VectaShield including DAPI (catalog \#H-1200; Vector Laboratories). Sections from all animals of the three experimental groups were processed together for immunohistochemistry and image analysis.

Fluorescence deconvolution tomography. Using a Leica DM6000 epifluorescence microscope, a $63 \times$ oil-immersion objective (numerical aperture 1.4) and an ORCA-ER (Hamamatsu) camera, digital image $z$-stacks were collected through $3 \mu \mathrm{m}(0.2 \mu \mathrm{m}$ steps $)$ for $136 \times 105 \mu \mathrm{m}$ sample fields that were centered on layer I of infralimbic or parietal cortex. Layer I was selected for analysis because of the relative paucity of neuronal cell bodies. Images were systematically collected from evenly spaced sections approximately positioned from 3.72 to $2.52 \mathrm{~mm}$ anterior to bregma for infralimbic cortex and from 2.52 to $2.04 \mathrm{~mm}$ anterior to bregma for somatosensory cortex (Paxinos and Watson, 2007). An experimenter confirmed full penetration of immunolabeling through the entire sampled $3 \mu \mathrm{m}$ depth. For each region and section, one or two $z$-stacks were collected from the target field. $z$-Stacks were processed for restorative deconvolution (Volocity 5.0; PerkinElmer Life and Analytical Sciences), and in-house software was used to normalize background fluorescence intensity and construct 3D montages of each $42,840 \mu \mathrm{m}^{3}$ sample field. Automated systems were then used to count and measure 3D volumes and fluorescence intensities of immunolabeled elements (Rex et al., 2009; Seese et al., 2012). This automated image analysis only quantified objects that satisfied the size and eccentricity constraints of synapses, that were present in multiple density thresholds, and whose boundaries were fully contained within the $z$-stack, similar to the associated point count rule used in stereological techniques (Moyer et al., 2012). Objects detected by only one threshold, and thus likely to be immunostaining artifacts, were excluded from quantification.

Statistical analyses. Statistical significance ( $p \leq 0.05$ ) was assessed using ANOVA with planned post hoc comparisons, the two-tailed Student's $t$ test, the $\chi^{2}$ test, or linear regression analysis. For both cortical fields, measures were collected from at least eight $z$-stacks, across at least four tissue sections, per brain. Counts of immunopositive $(+)$ elements within each $z$-stack were averaged for each region and brain. A single $n$ was considered to be a separate animal for all analyses. In analyses of immunolabeled volumes and intensities, the frequency distributions of labeled elements were plotted across $0.001 \mu \mathrm{m}^{3}$ and 5 unit bins, respectively, and divided by the total number of sections imaged.

\section{Results}

\section{PSD95 immunolabeling is homogeneously distributed within} infralimbic cortex layer I

Data were collected from the two outbred lines (Schulz et al., 2010) and from unrelated Sprague Dawley control rats, the latter to identify effects of selective breeding that do not relate to helplessness. Tissue sections were processed for immunofluorescence localization of PSD95, a protein that is distributed evenly across excitatory PSDs (Aoki et al., 2001; Megías et al., 2001). Images of a $136 \times 105 \times 3 \mu \mathrm{m}$ field were collected from layer I within the cytoarchitectonic boundaries of infralimbic cortex, the rat homolog of Brodmann area 25 (Ongür et al., 2003). Two contiguous zones were sampled for each section. As noted, these sections were not positioned at precisely the same planes along the anteroposterior dimension of the target cortex. The resultant sample covered $50 \%$ of the depth (mediolateral axis) and $20 \%$ of the height (dorsoventral axis) of infralimbic cortex layer I within sections analyzed. We do not assume that the results described here necessarily apply to the remainder of the layer. Image $z$-stacks underwent restorative deconvolution, followed by $3 \mathrm{D}$ reconstructions from the contiguous optical planes; numbers, volumes, and immunolabeling intensities of synaptic elements fully contained within the sample fields were then quantified using automated systems (Rex et al., 2009; Seese et al., 2012). 
Approximately 250,000 synapses were individually analyzed for infralimbic cortex for each rat. It is important to note that the thickness of infralimbic cortex layer I did not differ for the three groups of rats (control, $289 \pm 9 \mu \mathrm{m} ; \mathrm{cNLH}, 283 \pm 11 \mu \mathrm{m}$; cLH, $279 \pm 14 \mu \mathrm{m})$.

We first tested whether PSD95 labeling was evenly distributed throughout the sampling fields by subdividing each field into 10 $\mu \mathrm{m}$ segments parallel to the dorsoventral axis. Averaging the values across all rats in a group reduced the variance for individual segments and thus increased the sensitivity of the test for regional heterogeneity. For each group, the percentage of the total PSD95immunoreactive (IR) elements of the field present in each segment varied little across the dorsoventral axis (Fig. $1 A$; control, $9.86 \pm 0.08 \% ; \mathrm{cLH}, 9.86 \pm 0.10 \% ; \mathrm{cNLH}, 9.85 \pm 0.08 \%) . \mathrm{A} \chi^{2}$ test of this analysis confirmed that the observed values did not differ significantly from what would be expected from a homogeneous population (control, $\chi^{2}=0.18, \mathrm{df}=9, p>0.90$; $\mathrm{cLH}$, $\left.\chi^{2}=0.21, \mathrm{df}=9, p>0.90 ; \mathrm{cNLH}, \chi^{2}=0.08, \mathrm{df}=9, p>0.90\right)$. Repeating these exercises by subdividing each sample field dorsoventrally into $10 \mu \mathrm{m}$ segments along the mediolateral axis produced similar results (control, $7.48 \pm 0.05 \%, \chi^{2}=0.08$, $\mathrm{df}=12$, $p>0.90 ; \mathrm{cLH}, 7.49 \pm 0.06 \%, \chi^{2}=0.12, \mathrm{df}=12, p>0.90 ; \mathrm{cNLH}$, $\left.7.49 \pm 0.05 \%, \chi^{2}=0.08, \mathrm{df}=12, p>0.90\right)$. To address the possibility that positive and negative slopes occur across animals because of individual differences, and thus cancel out dimensional effects in group averages, we calculated means and SDs for absolute slopes of each image. This produced the following results for $x$-axis (control, $0.74 \pm 0.58 ; \mathrm{cLH}, 1.44 \pm 1.10 ; \mathrm{cNLH}$, $1.01 \pm 1.24$ ) and $y$-axis (control, $1.78 \pm 1.20$; cLH, $1.92 \pm 1.30$; $\mathrm{cNLH}, 1.51 \pm 1.76)$; in these measures, a slope of 1 represents a variation of 10 synapses per $10 \mu \mathrm{m}$ segment, which represents $\sim 0.004 \%$ of the total synapses surveyed per image. Regression analyses indicate that none of these values approaches statistical significance $\left(R^{2}>0.28\right.$ and $p>0.11$ for all cases $)$.

The above parametric tests for regional differences might miss gradients in the numerical density of immunostaining along one or more of the three axes. We tested for directionality by calculating the gradient in all directions of each image. As depicted in Figure $1 B$, each sample field was divided into 1000 blocks ( 10 in each axis), and then object numerical densities of every other single block were subtracted from its neighbor. These differences were then summed to give the total directionality along each axis.
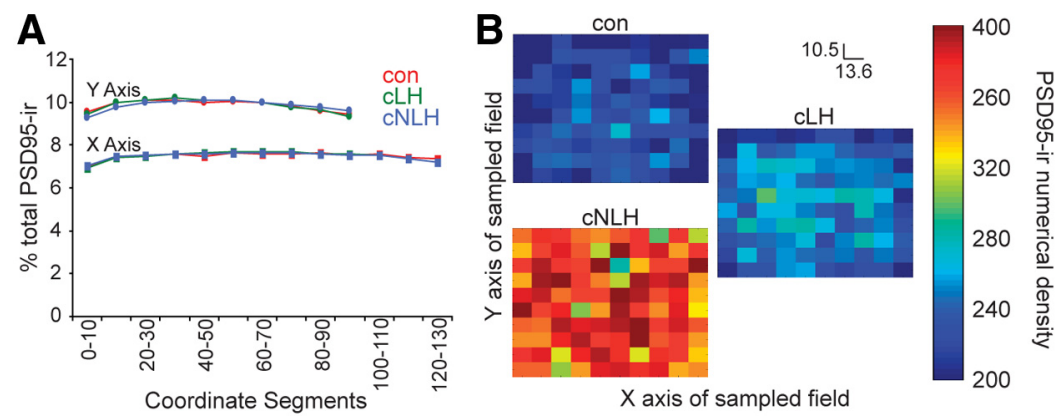

Figure 1. PSD95-IR clusters are evenly distributed across infralimbic fields quantified by fluorescence deconvolution tomography. $\boldsymbol{A}$, Top, Each sample field surveyed was divided mediolaterally into $10 \mu \mathrm{m}$ dorsoventral segments and dorsoventrally into 10 $\mu \mathrm{m}$ mediolateral segments. Plot shows percentage of total PSD95-IR elements within each $10 \mu \mathrm{m}$ segment for control (con), $\mathrm{CLH}$, and cNLH rats. The absolute percentage is greater in the y dimension than the x because the latter contains more $10 \mu \mathrm{m}$ segments. Note the small variability within each segment (error bars are occluded by data points); values are not significantly different from what would be expected from a homogeneous sample field ( $p>0.90$ for both dimensions). $\boldsymbol{B}$, Representative heat maps of PSD95 ${ }^{+}$object numerical densities across the $x$ - and $y$-axes of the sampled field for control, $\mathrm{CLH}$, and cNLH groups. Color denotes the incidence of immunolabeled elements per $10.5 \times 13.6 \mu \mathrm{m}$ block, as indicated by the scale on the right. The variation across the sample field was found to be relatively small with no clear gradients in any dimension.
This is represented in Equations $1-3$, where $M$ is the matrix of PSD95-IR element numerical density, and $\Delta x, \Delta y$, and $\Delta z$ are the calculated gradients along each axis:

$$
\begin{aligned}
& \Delta x=2 \sum_{i=1}^{n} \sum_{k=1}^{n} \sum_{j=1}^{n / 2}\left(M_{i(2 j-1) k}-M_{i 2 j k}\right), \\
& \Delta y=2 \sum_{j=1}^{n} \sum_{k=1}^{n} \sum_{i=1}^{n / 2}\left(M_{(2 i-1) j k}-M_{2 i j k}\right), \\
& \Delta z=2 \sum_{i=1}^{n} \sum_{j=1}^{n} \sum_{k=1}^{n / 2}\left(M_{i j(2 k-1)}-M_{i j 2 k}\right) .
\end{aligned}
$$

The calculations confirmed that the numerical density directionality in all sample fields surveyed is $214 \pm 467$ (mean \pm SD) in the positive $x$ direction, $70.2 \pm 441$ in the positive $y$ direction, and $508 \pm 1218$ in the positive $z$ direction. These mean values represented $0.8,0.03$, and $1.9 \%$ of the total synapses quantified. ANOVA confirmed a lack of interaction between rat strain and (he $x$ and $y$ directions ( $p>0.30$ for both). A was present $(p<0.05)$. Additional analyses confirmed that this effect was secondary to small differences unlikely to influence the arge synaptic populations quantified. In particular, control animals exhibited 2.0 and $1.2 \%$ more synapses at the top of their fected synaptic measurements through the anteroposterior axis infralimbic cortex by calculating the difference of PSD95 ${ }^{+}$ bject numerical densities between the most rostral and cauda anteroposterior differences $(p>0.95)$. We conclude from these analyses that staining variations are distributed homogeneously across the subzone of infralimbic cortex examined. It remains possible that regional variation exists in infralimbic fields not included in the study.

\section{PSD95 immunofluorescence intensity is lower in infralimbic cortex of cLH rats}

The numerical density of synapse-sized PSD95 ${ }^{+}$clusters in infralimbic sample fields (Fig. $2 A-C$ ) varied little between control rats and was nearly identical to cLH counts $(23,750 \pm$ 864 vs $23,339 \pm 860$ per $136 \times 105 \times 3 \mu \mathrm{m}$ sampling zone), indicating that the cLH phenotype does not arise from a loss of excitatory synapses. Frequency distribution curves for sizes of PSD95 ${ }^{+}$synapses in control and cLH rats had a strong positive skew, but the cLH group had fewer large contacts (Fig. 2D,E). This resulted in significantly lower median volumes for $\mathrm{PSD}^{+}{ }^{+}$elements in cLH rats (control, $0.040 \pm 0.001 \mu \mathrm{m}^{3} ; \mathrm{cLH}, 0.033 \pm 0.001$ $\left.\mu \mathrm{m}^{3} ; p=0.004\right)$. The difference between groups was more striking for PSD95 immunolabeling intensity: the $\mathrm{PSD}^{+}{ }^{+}$object intensity frequency distribution was strongly left shifted in cLH rats relative to controls (Fig. $2 F$ ). As such, median fluorescence intensity values were markedly lower in cLH rats (control, $108.1 \pm 1.4$ units; cLH, $100.5 \pm 0.8$ units; $p=0.00007)$. We evaluated the shape of the cumulative probability curves for intensity distributions for individual rats (Fig. 2G) using the Boltzmann sigmoidal fit and then 

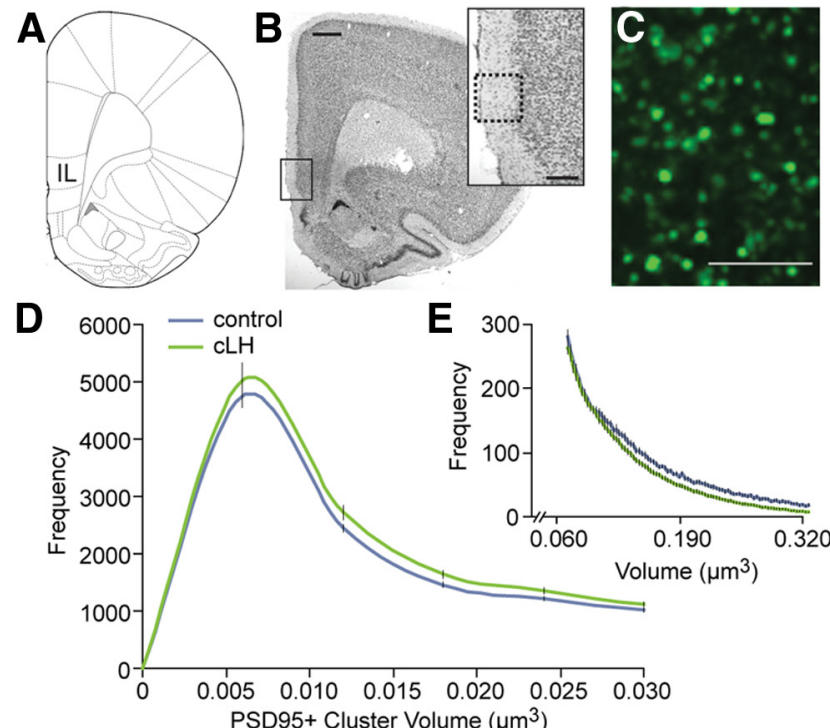

$\mathbf{F}$

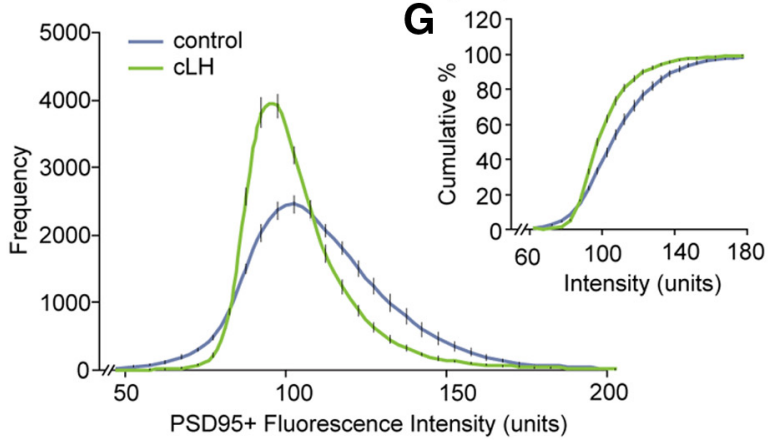

Figure 2. Synaptic PSD95 immunoreactivity is reduced in infralimbic cortex in the cLH rat model of chronic depression. $A$, Schematic of a coronal section through rostral forebrain identifying the infralimbic (IL) area of medial prefrontal cortex ( $+3 \mathrm{~mm}$ from bregma) (Paxinos and Watson, 2007). $\boldsymbol{B}$, Nissl-stained section from a control Sprague Dawley rat taken from the same level as the schematic (scale bar, $500 \mu \mathrm{m}$ ). The box in the larger image marks the infralimbic sample field of analysis; inset shows a higher-power image of infralimbic cortex layer I (dashed box; scale bar, $250 \mu \mathrm{m})$. C, Deconvolved image shows that PSD95 immunoreactivity in infralimbic layer I is exclusively localized to discrete clusters that fall within the size range of excitatory synapses (scale bar, $2.5 \mu \mathrm{m}$ ). D, Frequency distributions of $\mathrm{PSD}^{+}{ }^{+}$synapse sizes in infralimbic cortex of control Sprague Dawley (blue; $n=8$ ) and (LH (green; $n=12$ ) rats. $\boldsymbol{E}$, Right-most tail of the PSD95 ${ }^{+}$synapse size frequency distributions for control and CLH rats, showing that the latter group contains fewer very large synapses. $F$, Frequency distributions of PSD95 ${ }^{+}$cluster fluorescence intensities for control (blue; $n=8$ ) and cLH (green; $n=12$ ) rats: there is a strong leftward shift for $\mathrm{CLH}$ rats relative to controls with a significant reduction in median values ( $p=0.00007$ ). G, Cumulative probability curves for mean control (blue) and CLH (green) PSD95 ${ }^{+}$intensities in infralimbic cortex; comparing the slopes of these curves with a Boltzmann sigmoidal fit produced a robust statistical difference between $\mathrm{CLH}$ and control groups $(p=0.0007)$.

compared the means for each group to test the reliability of the curve shift in Figure $2 F$. The difference between CLH and control groups was highly significant $(p=0.0007)$. These analyses suggest that, within the synapse-sized immunolabeled elements, concentrations of PSD95 are markedly reduced in cLH rats relative to controls.

We confirmed that the loss of PSD95 immunoreactivity was not influenced by differences in synapse volumes by comparing the immunolabeling intensities of contacts across $90 \%$ of the volume distribution described in Figure $2 D$ (i.e., minus the righthand tail of the distribution). The leftward shift in labeling intensities for CLH rats found when evaluating the entire population was also evident when restricting analysis to contacts with the
A

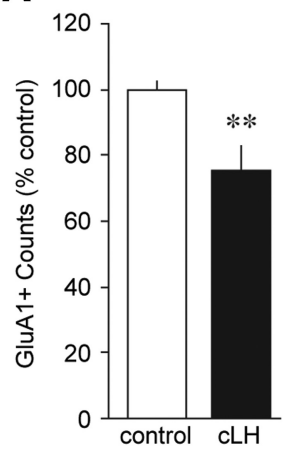

B

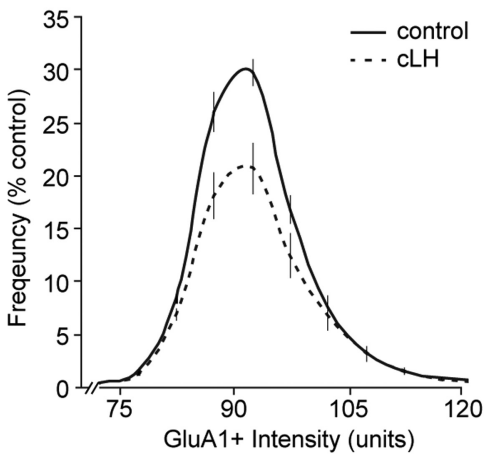

Figure 3. Numerical densities of GluA1-containing AMPA receptors are reduced in infralimbic fields from cLH rats. $A$, Bar graph shows that CLH rats $(n=12)$ had $\sim 25 \%$ fewer synapsesized clusters of GluA1 immunoreactivity in infralimbic cortex than did control Sprague Dawley rats $\left(n=8,{ }^{* *} p=0.008\right.$; values normalized to same-cohort control mean). $\boldsymbol{B}$, Fluorescence intensity frequency distributions for GluA1 ${ }^{+}$clusters in control (solid line; $n=8$ ) and $\mathrm{CLH}$ (dashed line; $n=12$ ) rats illustrate that reductions in GluA1 shown in $A$ occur across all intensities and are not secondary to differences in mean labeling intensity (CLH values normalized to the mean GluA1 count of the same cohort control group).

same mean volumes in the two groups; as such, median labeling intensity values were still significantly less in the CLH group after eliminating the largest $10 \%$ of the contacts (control, $105.8 \pm 0.9$ units; cLH, $99.6 \pm 0.7$ units; $p=0.00004$ ). We conclude that, relative to controls, the major synaptic correlate of the cLH phenotype is a reduction in the synaptic concentration of PSD95.

\section{Numbers of $\mathrm{GluA}^{+}{ }^{+}$elements are lower in $\mathrm{CLH}$ rats}

Reductions in PSD95 immunolabeling intensities in cLH rats raise the question of whether there were also changes in synapsesized clusters of AMPA receptors. We tested this using immunostaining for the GluA1 subunit of the receptor in sample fields from infralimbic cortex of control and cLH rats. Possibly related to the loss of PSD95 immunofluorescence intensity, mean $\mathrm{GluA}^{+}$element counts for the cLH group were reduced by $\sim 25 \%$ relative to values from controls $(p=0.008$; Fig. $3 A$ ). The losses were not secondary to a reduction in the mean size or immunofluorescence intensity of GluA $1^{+}$clusters, because these values were not different between groups: $0.018 \pm 0.001$ versus $0.018 \pm 0.001 \mu \mathrm{m}^{3}$ for volume and $94.6 \pm 0.4$ versus $93.5 \pm 0.5$ units for fluorescence intensity for control and cLH rats, respectively. As anticipated from these results, the loss of $\mathrm{GluA}^{+}{ }^{+}$elements occurred across the full range of labeling intensities (Fig. $3 B$ ). These results add a second correlate to the cLH phenotype: a loss of GluA1-containing AMPA receptors from a significant population of excitatory synapses.

\section{Numbers of PSD95 ${ }^{+}$synapses are elevated in infralimbic cortex of cNLH rats}

We also tested a group of rats bred to be resistant to learned helplessness (cNLH). In marked contrast to CLH measurements, the numerical density of PSD $95^{+}$contacts was $>30 \%$ greater in infralimbic sample fields from cNLH rats compared with controls (Fig. 4A). ANOVA confirmed that differences between cNLH, cLH, and control groups were significant $(p<0.0001)$, with counts from $\mathrm{cNLH}$ rats being greater than those from either cLH or control rats $(p<0.001)$. The frequency distribution of PSD95 ${ }^{+}$cluster volumes had the same shape in cNLH as in control rats, but the curve was left shifted in the cNLH group (Fig. $4 B$ ), resulting in reduced median volumes (control, $0.038 \pm$ 

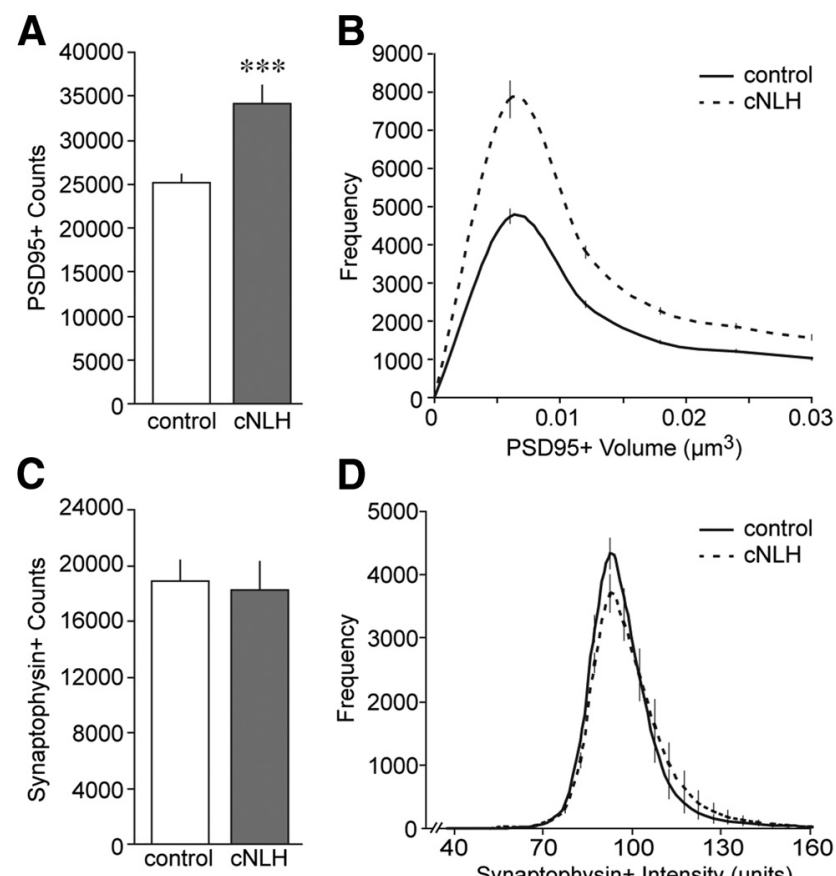

D

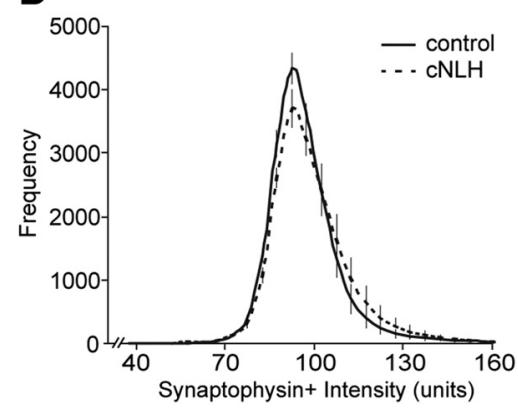

Figure 4. Rats bred for resistance to helplessness (CNLH) exhibit elevated numerical densities of non-innervated PSDs. $A$, Bar graph shows that, for sample fields within infralimbic cortex, the cNLH rats $(n=4)$ have $\sim 30 \%$ more PSD $95^{+}$clusters than do control rats $\left(n=8\right.$, ${ }^{* *} p<$ 0.001). $B$, Frequency distribution of PSD $95^{+}$element volumes in infralimbic cortex for $C$ NLH rats (dashed line; $n=4$ ) was slightly left shifted compared with control rats (solid line; $n=8$ ), resulting in a significant decrease in median volume $(p=0.001) . C, D$, There were no differences between control (solid line; $n=8$ ) and $\mathrm{cNLH}$ (dashed line; $n=4$ ) rats in numerical densities $(\boldsymbol{C})$ or labeling intensities $(\boldsymbol{D})$ of synaptophysin ${ }^{+}$elements.

$\left.0.0003 \mu \mathrm{m}^{3} ; \mathrm{cNLH}, 0.030 \pm 0.003 \mu \mathrm{m}^{3} ; p=0.001\right)$. As described above (Fig. 2D), a comparable volume reduction was evident for $\mathrm{PSD}{ }^{+}$clusters in cLH infralimbic sample fields, indicating that the decrease in synapse volume is not related to learned helplessness. Unlike the case for cLH rats, the median immunolabeling intensity of PSD $95^{+}$elements was unaffected in cNLH rats (control, $105.7 \pm 1.0$ units; cNLH, $105.2 \pm 2.0$ units; $p>0.80)$. Moreover, there was no evidence in the cNLH group for the decrease in the numerical density of synapse-sized GluA1 clusters found in the cLH group $(p>0.40)$.

The absence of a clear increase in GluA ${ }^{+}$clusters in infralimbic cortex of cNLH rats raised the possibility that the greater numerical densities of PSD95 ${ }^{+}$structures in this layer are not associated with presynaptic elements. We tested this by immunolabeling additional sections from the same rats for the transmitter vesicle protein synaptophysin. There were no differences between control and cNLH groups with regard to numerical densities (Fig. $4 C$ ) or fluorescence intensity distributions (Fig. 4D) of synaptophysin ${ }^{+}$terminals in infralimbic sample fields. We conclude that the $\mathrm{cNLH}$ phenotype consists of an increase in PSDs lacking presynaptic innervation.

\section{$\mathrm{GABA}_{\mathrm{A}} \mathrm{R}^{+}$synapses are unaffected in $\mathrm{cLH}$ and $\mathrm{cNLH}$ rats}

The differences described above for excitatory synapses did not hold for inhibitory contacts immunolabeled for the $\mathrm{GABA}_{\mathrm{A}} \mathrm{R}$ (Fig. 5A). In infralimbic fields, total numerical densities of $\mathrm{GABA}_{\mathrm{A}} \mathrm{R}^{+}$elements were reduced in $\mathrm{cLH}$ and $\mathrm{cNLH}$ groups compared with controls (Fig. $5 B$; ANOVA, $p=0.03$; control vs cLH, $p<0.05)$. Moreover, median immunolabeling intensities and sizes of $\mathrm{GABA}_{\mathrm{A}} \mathrm{R}^{+}$contacts were not different between the
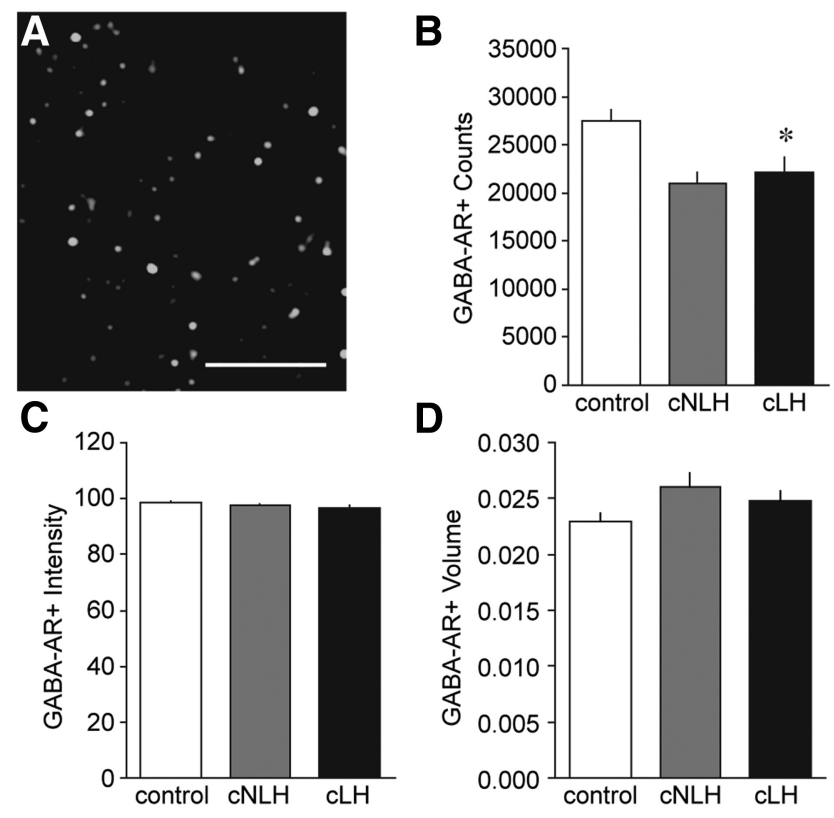

Figure 5. Inhibitory synapse measures were comparable in infralimbic cortical fields from $\mathrm{CLH}$ and $C \mathrm{NLH}$ rats. $\boldsymbol{A}$, Immunolabeling for the $\mathrm{GABA}_{\mathrm{A}} \mathrm{R} \beta$ subunit in infralimbic cortex is limited to synapse-sized clusters (scale bar, $5 \mu \mathrm{m}$ ). $B$, Numerical densities of $G_{A B A_{A}} R$ clusters were less in infralimbic cortical fields for both CLH $(n=12)$ and $\mathrm{CNLH}(n=4)$ rats compared with Sprague Dawley control rats $(n=8)$. The control versus $\mathrm{CLH}$ effect was significant $\left({ }^{*} p<0.05\right)$. C, D,

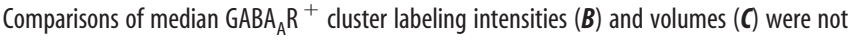
different between control, $\mathrm{CLH}$, and $\mathrm{CNLH}$ rats.
A

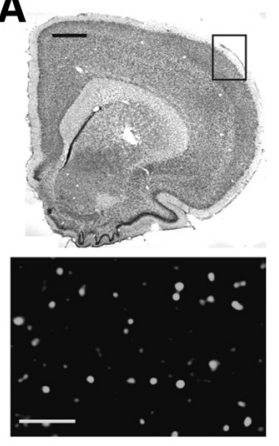

B

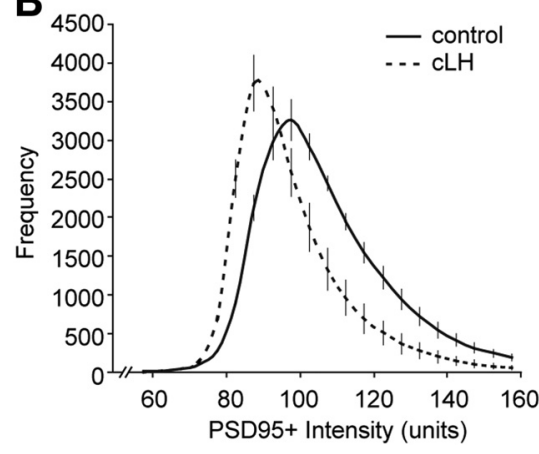

Figure 6. Lower levels of PSD95 are not limited to infralimbic cortex of congenitally depressed rats. $A$, Top, Nissl-stained section through a control Sprague Dawley forebrain, caudal to that illustrated in Figure $1 B$, shows the parietal (primary somatosensory forelimb) cortex sampling zone (box) (scale bar, $500 \mu \mathrm{m}$ ). Bottom, Representative deconvolved image shows PSD95 immunolabeling in the parietal sample field of a cNLH rat (scale bar, $2.5 \mu \mathrm{m}$ ). B, Frequency distributions of PSD95 ${ }^{+}$cluster intensities in parietal cortex layer l of control (solid line; $n=4$ ) and $\mathrm{CLH}$ (dashed line; $n=7$ ) rats. Note the leftward shift for CLH compared with control rats, similar to that observed in infralimbic cortex (see Fig. 2F).

three groups (Fig. 5C,D). Thus, GABAergic synapses did not exhibit the pattern of changes found for excitatory contacts in either cLH or cNLH infralimbic cortex.

\section{PSD95 levels are lower in cLH somatosensory cortex}

Finally, we performed tests of whether the above-described effects on PSD95 immunolabeling are distributed across the cortex by evaluating layer I of primary somatosensory neocortex (Fig. $6 A$ ). As found in infralimbic cortex, the mean immunolabeling intensity of PSD95 ${ }^{+}$clusters was reduced in this parietal field of cLH rats compared with controls (Fig. 6B): differences in the 
Table 1. Summary of synaptic changes relative to control Sprague Dawley rats

\begin{tabular}{|c|c|c|c|c|c|c|}
\hline & $\mathrm{CLH}$ & & & CNLH & & \\
\hline \multicolumn{7}{|c|}{ Infralimbic cortex } \\
\hline PSD95 & $C \leftrightarrow$ & $V \downarrow$ & $\mathrm{I} \downarrow \downarrow^{a}$ & $c \uparrow \uparrow^{a}$ & $v \downarrow$ & $\mid \leftrightarrow$ \\
\hline GluR1 & $C \downarrow^{a}$ & $V \leftrightarrow$ & $\mid \leftrightarrow$ & $C \leftrightarrow$ & $\mathrm{V} \leftrightarrow$ & $\mid \leftrightarrow$ \\
\hline $\mathrm{GABA}_{\mathrm{A}} \mathrm{R}$ & $C \downarrow$ & $\mathrm{V} \leftrightarrow$ & $\mid \leftrightarrow$ & $c \downarrow$ & $\mathrm{V} \leftrightarrow$ & $\mid \leftrightarrow$ \\
\hline \multicolumn{7}{|c|}{ Parietal cortex } \\
\hline PSD95 & $C \leftrightarrow$ & $V \leftrightarrow$ & $\mid \downarrow^{a}$ & $C \leftrightarrow$ & $\mathrm{V} \leftrightarrow$ & $\mid \leftrightarrow$ \\
\hline
\end{tabular}

median values of the distributions were significant $(p=0.05)$. Although the percentage decrease in median PSD95 immunolabeling intensity of cLH rats compared with controls was less in primary somatosensory neocortex $(4.7 \pm 1.4 \%)$ than in infralimbic cortex $(7.1 \pm 0.07 \%)$, this difference was not statistically significant $(p=0.10)$. Thus, the loss of PSD95 immunolabeling intensity in CLH rats is not region specific. In contrast to infralimbic measurements, the numerical density of PSD $95^{+}$contacts in parietal fields did not differ between control and cNLH rats. Counts of $\mathrm{GABA}_{\mathrm{A}} \mathrm{R}^{+}$elements did not differ between parietal fields in control rats and the two outbred lines.

\section{Discussion}

The present studies constitute a first test for differences in glutamatergic synapses between related rat strains and between cortical regions within a strain using fluorescence deconvolution tomography. This automated method counts and measures volumes and labeling intensities of synapses within large fields and

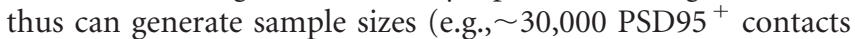
per field) needed to detect subtle differences (Rex et al., 2009; Seese et al., 2012).

Because we surveyed only a proportion of the total layer I infralimbic cortex, we first performed stringent tests for heterogeneity in our sample fields that could introduce significant sampling biases (Dorph-Petersen and Lewis, 2011). Tests of data directionality and object numerical density within systematically segregated segments along the sample field did not uncover any evidence for heterogeneity. Nonetheless, the analyses we present here in a defined subcomponent of infralimbic cortex cannot be assumed to hold for the entire cytoarchitectonic field.

We subsequently used fluorescence deconvolution tomography to test whether components of excitatory transmission are disturbed in the congenital learned helplessness model of depression. Numerous studies support a "glutamate hypothesis" for chronic depression, but evidence at the level of individual synapses is lacking (Sanacora et al., 2004, 2012; Sartorius et al., 2007; Yüksel and Ongür, 2010; Hascup et al., 2011). Our results indicate that the density of synapse-sized clusters of PSD95 is reduced in layer I sample fields of infralimbic cortex, a region associated with depression, as well as within parietal neocortex of cLH rats. PSD95 anchors AMPA receptors and signaling proteins to the PSD (Kim and Sheng, 2004). Thus, changes in synaptic PSD95 concentrations could affect the functional properties of these connections. In accord with this, the numerical density of synapse-sized clusters of the AMPA receptor subunit GluA1 was reduced in $\mathrm{CLH}$ rats (Table 1 ). Because controls and $\mathrm{cLH}$ rats exhibited comparable numerical density of PSD95 ${ }^{+}$synapses, the reduced GluA1 ${ }^{+}$elements suggest that $\mathrm{PSD}^{+}{ }^{+}$contacts have AMPA receptors with an abnormal subunit composition. Alternatively, the GluA1 results may be representative of other AMPA receptor subunits, in which case the $\mathrm{cLH}$ phenotype would include a sizable population of weak or silent synapses (Kerchner and Nicoll, 2008). Analyses of other AMPA receptor subunits should distinguish between these two versions of a "defective synapse" hypothesis. Independent of the exact mechanism, that multiple measurements of many markers show different group-specific effects strengthens the validity of our results while providing assurance that differential tissue shrinkage did not contribute significant biases in our analyses. One would predict that evidence of differential shrinkage would manifest as directionally consistent changes in markers tested.

In contrast to effects on excitatory synapses, we did not find differences in the incidence or immunofluorescence intensity of GABAergic (i.e., $\mathrm{GABA}_{\mathrm{A}} \mathrm{R}^{+}$) contacts between $\mathrm{cLH}$ and $\mathrm{cNLH}$ rats. GABAergic systems are disturbed in affective disorders: fewer GABAergic neurons are found in anterior cingulate cortex in tissue from bipolar patients compared with controls, and antidepressants reverse a GABA deficit in models of depression (Brambilla et al., 2003). It remains possible that GABAergic innervation differs between groups in layers other than layer I.

PSD95 organizes synaptic elements crucial for synaptic plasticity and memory (Kim and Sheng, 2004). Therefore, reduced PSD95 levels could impair the ability of synapses to adjust to changing circumstances and to influence infralimbic networks involved in emotional behavior. Additional studies are needed to determine whether aversive stimuli expected to exacerbate mood symptoms influence infralimbic PSD95 levels in the cLH rats, especially in light of recent evidence that stress increases hippocampal PSD95 in the Flinders model of depression (Wegener et al., 2010). PSD95 also interacts with the serotonin 2A receptor (Xia et al., 2003), a target of antidepressants and whose concentration is abnormal in cortex of depressed patients (Celada et al., 2004; Shelton et al., 2009). Although it is unlikely that the sparse population of serotonergic synapses contributed significantly to results described here, subnormal levels of PSD95 might also be present at biogenic amine connections. Thus, reductions in PSD95 could be an originating locus for different components of affective disorders.

It is unclear why depression would disturb glutamatergic synapses in the manner described here. Astroglial sequestration of extracellular glutamate is reduced in cLH rats (Zink et al., 2010), an effect that would lead to extended glutamate receptor activation after high-frequency afferent activity. Given the intimate relationship between glutamate receptors and synaptic organization, prolonged stimulation could result in reduced concentrations of PSD95 and GluA1. As noted, decreased levels of PSD95 and NMDA receptor subunits have been reported in frontal cortex of patients with MDD (Feyissa et al., 2009). This raises the possibility that the synaptic disturbances described here provide conserved biomarkers that might be used in evaluating experimental treatments for aberrant mood control.

We assessed fields in layer I primarily because of its relative sparsity of cell bodies. Although additional studies are needed to test whether the observed effects occur in deeper layers, it should be noted that infralimbic cortex layer I receives afferents from midline thalamic structures (Vertes and Hoover, 2008), including the paratenial nucleus, which in turn are innervated by the suprachiasmatic nucleus of the hypothalamus (Morin et al., 1994), a "clock" structure strongly implicated in mood control (McClung, 2011). The central locus of layer I in this circuit suggests that it is an appropriate site for testing for synaptic abnormalities in a model of depression.

It is worth considering the degree to which protein markers, such as PSD95 and GABA $\mathrm{A}$, can be used as proxies for synapses 
in morphometric studies and whether extrasynaptic receptors might contribute to analyses using the present techniques. Previous transmission electron microscopic work has shown that PSD95 ${ }^{+}$clusters are concentrated exclusively at asymmetric synapses and are present at the majority of those synapses (Aoki et al., 2001; Sassoé-Pognetto et al., 2003). Similarly freeze-fracture immunogold electron microscopy has confirmed that $\mathrm{GABA}_{\mathrm{A}} \mathrm{R}^{+}$ clusters are localized to synapses and correspond strongly to the size of those synapses, and that the extrasynaptic membrane exhibits only low-density $\mathrm{GABA}_{\mathrm{A}} \mathrm{R}$ immunolabeling (Kasugai et al., 2010). Thus, extrasynaptic labeling would not be expected to contribute to measures of PSD95 ${ }^{+}$or $\mathrm{GABA}_{\mathrm{A}} \mathrm{R}^{+}$elements in the present work. However it is likely that, because of factors such as incomplete tissue penetration by antibodies, our analyses underestimate numbers of layer I synapses. Comparisons of synapse counts derived from fluorescence deconvolution tomography to previous electron microscopic studies of hippocampal field CA1 stratum radiatum suggest that PSD95 immunofluorescence detects $\sim 40 \%$ of the structurally identified asymmetric synapses within a given 3D sample field (Fiala and Harris, 2001; Chen et al., 2007). Unfortunately, we do not have appropriate numerical values to approximate the proportion of $\mathrm{GABA}_{\mathrm{A}} \mathrm{R}$-containing synapses detected here. Nevertheless, because the present studies evaluated tissue from all groups processed identically and together and because of the relative homogeneity of PSD95 immunolabeling observed in layer I across all groups (Fig. 1), this underestimation is not likely to influence the effects of strain observed here.

The breeding program that led to the cLH line also produced cNLH rats that are resistant to learned helplessness relative to control rats (Schulz et al., 2010). The cNLH animals did not exhibit the loss of PSD95 or GluA1 in cortical fields in cLH rats but instead an increased numerical density of PSD $95^{+}$clusters. This effect was not accompanied by an increase in synaptophy$\sin ^{+}$presynaptic elements, indicating that the added PSD95 ${ }^{+}$ clusters reflect either large numbers of non-innervated PSDs or $\mathrm{PSD}^{+} 5^{+}$synapse-sized clusters in extrasynaptic space. Either way, resistance to depression is associated with an increase in "synapse-ready" elements. These results are intriguing in light of evidence that ketamine, a drug that induces BDNF (Autry et al., 2011), provides relief in many depressed subjects (Bunney and Bunney, 2012) and triggers spine formation in frontal cortex of adult rats (Li et al., 2010). Nonetheless, the resistance to learned helplessness in cNLH rats may chronically reflect similar mechanisms as those induced by antidepressants.

\section{References}

Aoki C, Miko I, Oviedo H, Mikeladze-Dvali T, Alexandre L, Sweeney N, Bredt DS (2001) Electron microscopic immunocytochemical detection of PSD-95, PSD-93, SAP-102, and SAP-97 at postsynaptic, presynaptic, and nonsynaptic sites of adult and neonatal rat visual cortex. Synapse 40:239257. CrossRef Medline

Autry AE, Adachi M, Nosyreva E, Na ES, Los MF, Cheng PF, Kavalali ET, Monteggia LM (2011) NMDA receptor blockade at rest triggers rapid behavioural antidepressant responses. Nature 475:91-95. CrossRef Medline

Bai F, Li X, Clay M, Lindstrom T, Skolnick P (2001) Intra- and interstrain differences in models of "behavioral despair." Pharmacol Biochem Behav 70:187-192. CrossRef

Brambilla P, Perez J, Barale F, Schettini G, Soares JC (2003) GABAergic dysfunction in mood disorders. Mol Psychiatry 8:721-737, 715. CrossRef Medline

Bunney BG, Bunney WE (2012) Rapid-acting antidepressant strategies: mechanisms of action. Int J Neuropsychopharmacol 15:695-713. CrossRef Medline
Castrén E, Võikar V, Rantamäki T (2007) Role of neurotrophic factors in depression. Curr Opin Pharmacol 7:18-21. CrossRef Medline

Celada P, Puig M, Amargós-Bosch M, Adell A, Artigas F (2004) The therapeutic role of 5-HT1A and 5-HT2A receptors in depression. J Psychiatry Neurosci 29:252-265. Medline

Chen LY, Rex CS, Casale MS, Gall CM, Lynch G (2007) Changes in synaptic morphology accompany actin signaling during LTP. J Neurosci 27:53635372. CrossRef Medline

Delgado PL (2000) Depression: the case for a monoamine deficiency. J Clin Psychiatry 61 [Suppl 6]:7-11.

Dorph-Petersen KA, Lewis DA (2011) Stereological approaches to identifying neuropathology in psychosis. Biol Psychiatry 69:113-126. CrossRef Medline

Drevets WC, Price JL, Simpson JR Jr, Todd RD, Reich T, Vannier M, Raichle ME (1997) Subgenual prefrontal cortex abnormalities in mood disorders. Nature 386:824-827. CrossRef Medline

Drevets WC, Bogers W, Raichle ME (2002) Functional anatomical correlates of antidepressant drug treatment assessed using PET measures of regional glucose metabolism. Eur Neuropsychopharmacol 12:527-544. CrossRef Medline

Duman RS, Aghajanian GK (2012) Synaptic dysfunction in depression: potential therapeutic targets. Science 338:68-72. CrossRef Medline

Feyissa AM, Chandran A, Stockmeier CA, Karolewicz B (2009) Reduced levels of NR2A and NR2B subunits of NMDA receptor and PSD-95 in the prefrontal cortex in major depression. Prog Neuropsychopharmacol Biol Psychiatry 33:70-75. CrossRef Medline

Fiala JC, Harris KM (2001) Extending unbiased stereology of brain ultrastructure to three-dimensional volumes. J Am Med Inform Assoc 8:1-16. CrossRef Medline

Hajek T, Kozeny J, Kopecek M, Alda M, Höschl C (2008) Reduced subgenual cingulate volumes in mood disorders: a meta-analysis. J Psychiatry Neurosci 33:91-99. Medline

Hajszan T, Dow A, Warner-Schmidt JL, Szigeti-Buck K, Sallam NL, Parducz A, Leranth C, Duman RS (2009) Remodeling of hippocampal spine synapses in the rat learned helplessness model of depression. Biol Psychiatry 65:392-400. CrossRef Medline

Hascup KN, Hascup ER, Stephens ML, Glaser PE, Yoshitake T, Mathé AA, Gerhardt GA, Kehr J (2011) Resting glutamate levels and rapid glutamate transients in the prefrontal cortex of the Flinders Sensitive Line rat: a genetic rodent model of depression. Neuropsychopharmacology 36: 1769-1777. CrossRef Medline

Hirschfeld RM (2000) History and evolution of the monoamine hypothesis of depression. J Clin Psychiatry 61 [Suppl 6]:4-6.

Kasugai Y, Swinny JD, Roberts JD, Dalezios Y, Fukazawa Y, Sieghart W, Shigemoto R, Somogyi P (2010) Quantitative localisation of synaptic and extrasynaptic GABAA receptor subunits on hippocampal pyramidal cells by freeze-fracture replica immunolabelling. Eur J Neurosci 32:18681888. CrossRef Medline

Kerchner GA, Nicoll RA (2008) Silent synapses and the emergence of a postsynaptic mechanism for LTP. Nat Rev Neurosci [Erratum (2009) 10:242] 9:813-825. CrossRef Medline

Kessler RC, Berglund P, Demler O, Jin R, Koretz D, Merikangas KR, Rush AJ, Walters EE, Wang PS; National Comorbidity Survey Replication (2003) The epidemiology of major depressive disorder: results from the National Comorbidity Survey Replication (NCS-R). JAMA 289:3095-3105. CrossRef Medline

Kim E, Sheng M (2004) PDZ domain proteins of synapses. Nat Rev Neurosci 5:771-781. CrossRef Medline

Kim HW, Rapoport SI, Rao JS (2010) Altered expression of apoptotic factors and synaptic markers in postmortem brain from bipolar disorder patients. Neurobiol Dis 37:596-603. CrossRef Medline

Li N, Lee B, Liu RJ, Banasr M, Dwyer JM, Iwata M, Li XY, Aghajanian G, Duman RS (2010) mTOR-dependent synapse formation underlies the rapid antidepressant effects of NMDA antagonists. Science 329:959-964. CrossRef Medline

Li X, Tizzano JP, Griffey K, Clay M, Lindstrom T, Skolnick P (2001) Antidepressant-like actions of an AMPA receptor potentiator (LY392098). Neuropharmacology 40:1028-1033. CrossRef Medline

Li X, Witkin JM, Need AB, Skolnick P (2003) Enhancement of antidepressant potency by a potentiator of AMPA receptors. Cell Mol Neurobiol 23:419-430. CrossRef Medline 
Luscher B, Shen Q, Sahir N (2011) The GABAergic deficit hypothesis of major depressive disorder. Mol Psychiatry 16:383-406. CrossRef Medline

Machado-Vieira R, Salvadore G, Diazgranados N, Zarate CA Jr (2009) Ketamine and the next generation of antidepressants with a rapid onset of action. Pharmacol Ther 123:143-150. CrossRef Medline

Mayberg HS, Liotti M, Brannan SK, McGinnis S, Mahurin RK, Jerabek PA, Silva JA, Tekell JL, Martin CC, Lancaster JL, Fox PT (1999) Reciprocal limbic-cortical function and negative mood: converging PET findings in depression and normal sadness. Am J Psychiatry 156:675-682. Medline

Mayberg HS, Lozano AM, Voon V, McNeely HE, Seminowicz D, Hamani C, Schwalb JM, Kennedy SH (2005) Deep brain stimulation for treatmentresistant depression. Neuron 45:651-660. CrossRef Medline

McClung CA (2011) Circadian rhythms and mood regulation: insights from pre-clinical models. Eur Neuropsychopharmacol 21 [Suppl 4]: S683-S693. CrossRef

Megías M, Emri Z, Freund TF, Gulyás AI (2001) Total number and distribution of inhibitory and excitatory synapses on hippocampal CA1 pyramidal cells. Neuroscience 102:527-540. CrossRef Medline

Morin LP, Goodless-Sanchez N, Smale L, Moore RY (1994) Projections of the suprachiasmatic nuclei, subparaventricular zone and retrochiasmatic area in the golden hamster. Neuroscience 61:391-410. CrossRef Medline

Moyer CE, Delevich KM, Fish KN, Asafu-Adjei JK, Sampson AR, DorphPetersen KA, Lewis DA, Sweet RA (2012) Reduced glutamate decarboxylase 65 protein within primary auditory cortex inhibitory boutons in schizophrenia. Biol Psychiatry 72:734-743. CrossRef Medline

Norrholm SD, Ouimet CC (2001) Altered dendritic spine density in animal models of depression and in response to antidepressant treatment. Synapse 42:151-163. CrossRef Medline

Ongür D, Ferry AT, Price JL (2003) Architectonic subdivision of the human orbital and medial prefrontal cortex. J Comp Neurol 460:425-449. CrossRef Medline

Patel JG, Bartoszyk GD, Edwards E, Ashby CR Jr (2004) The highly selective 5-hydroxytryptamine (5-HT)2A receptor antagonist, EMD 281014, significantly increases swimming and decreases immobility in male congenital learned helpless rats in the forced swim test. Synapse 52:73-75. CrossRef Medline

Paxinos G, Watson C (2007) The rat brain in stereotaxic coordinates. London: Academic Press.

Rex CS, Chen LY, Sharma A, Liu J, Babayan AH, Gall CM, Lynch G (2009) Different Rho GTPase-dependent signaling pathways initiate sequential steps in the consolidation of long-term potentiation. J Cell Biol 186:8597. CrossRef Medline

Samuels BA, Hen R (2011) Neurogenesis and affective disorders. Eur J Neurosci 33:1152-1159. CrossRef Medline

Sanacora G, Gueorguieva R, Epperson CN, Wu YT, Appel M, Rothman DL, Krystal JH, Mason GF (2004) Subtype-specific alterations of gammaaminobutyric acid and glutamate in patients with major depression. Arch Gen Psychiatry 61:705-713. CrossRef Medline

Sanacora G, Treccani G, Popoli M (2012) Towards a glutamate hypothesis of depression: an emerging frontier of neuropsychopharmacology for mood disorders. Neuropharmacology 62:63-77. CrossRef Medline
Sartorius A, Mahlstedt MM, Vollmayr B, Henn FA, Ende G (2007) Elevated spectroscopic glutamate/gamma-amino butyric acid in rats bred for learned helplessness. Neuroreport 18:1469-1473. CrossRef Medline

Sassoé-Pognetto M, Utvik JK, Camoletto P, Watanabe M, Stephenson FA, Bredt DS, Ottersen OP (2003) Organization of postsynaptic density proteins and glutamate receptors in axodendritic and dendrodendritic synapses of the rat olfactory bulb. J Comp Neurol 463:237-248. CrossRef Medline

Schulz D, Mirrione MM, Henn FA (2010) Cognitive aspects of congenital learned helplessness and its reversal by the monoamine oxidase (MAO)-B inhibitor deprenyl. Neurobiol Learn Mem 93:291-301. CrossRef Medline

Schulz D, Smith D, Yu M, Lee H, Henn FA (2013) Selective breeding for helplessness in rats alters the metabolic profile of the hippocampus and frontal cortex: a 1H-MRS study at 9.4 T. Int J Neuropsychopharmacol 16:199-212. CrossRef Medline

Seese RR, Babayan AH, Katz AM, Cox CD, Lauterborn JC, Lynch G, Gall CM (2012) LTP induction translocates cortactin at distant synapses in wildtype but not Fmr1 knock-out mice. J Neurosci 32:7403-7413. CrossRef Medline

Shelton RC, Sanders-Bush E, Manier DH, Lewis DA (2009) Elevated 5-HT $2 \mathrm{~A}$ receptors in postmortem prefrontal cortex in major depression is associated with reduced activity of protein kinase A. Neuroscience 158: 1406-1415. CrossRef Medline

Shumake J, Poremba A, Edwards E, Gonzalez-Lima F (2000) Congenital helpless rats as a genetic model for cortex metabolism in depression. Neuroreport 11:3793-3798. CrossRef Medline

Vertes RP, Hoover WB (2008) Projections of the paraventricular and paratenial nuclei of the dorsal midline thalamus in the rat. J Comp Neurol 508:212-237. CrossRef Medline

Vollmayr B, Bachteler D, Vengeliene V, Gass P, Spanagel R, Henn F (2004) Rats with congenital learned helplessness respond less to sucrose but show no deficits in activity or learning. Behav Brain Res 150:217-221. CrossRef Medline

Wegener G, Harvey BH, Bonefeld B, Müller HK, Volke V, Overstreet DH, Elfving B (2010) Increased stress-evoked nitric oxide signalling in the Flinders sensitive line (FSL) rat: a genetic animal model of depression. Int J Neuropsychopharmacol 13:461-473. CrossRef Medline

Xia Z, Gray JA, Compton-Toth BA, Roth BL (2003) A direct interaction of PSD-95 with 5-HT2A serotonin receptors regulates receptor trafficking and signal transduction. J Biol Chem 278:21901-21908. CrossRef Medline

Yüksel C, Ongür D (2010) Magnetic resonance spectroscopy studies of glutamate-related abnormalities in mood disorders. Biol Psychiatry 68: 785-794. CrossRef Medline

Zink M, Vollmayr B, Gebicke-Haerter PJ, Henn FA, Thome J (2007) Reduced expression of complexins I and II in rats bred for learned helplessness. Brain Res 1144:202-208. CrossRef Medline

Zink M, Vollmayr B, Gebicke-Haerter PJ, Henn FA (2010) Reduced expression of glutamate transporters vGluT1, EAAT2 and EAAT4 in learned helpless rats, an animal model of depression. Neuropharmacology 58: 465-473. CrossRef Medline 